\title{
Determinants Affecting Knowledge of Healthcare Students towards Mental Health Challenges
}

\author{
Muhammad Zahid Iqbal', Abdul Nazer Ali', Mohd Baidi Bahari', Muhammad Shahid Iqbal'2,* \\ 'Department of Clinical Pharmacy and Pharmacy Practice, Faculty of Pharmacy, AIMST University, Bedong, Kedah Darul Aman, MALAYSIA. \\ 2Department of Clinical Pharmacy, College of Pharmacy, Prince Sattam bin Abdulaziz University, Al-kharj, SAUDI ARABIA.
}

\begin{abstract}
Objectives: The objective of the study was to evaluate the determinants affecting knowledge of healthcare students towards mental health challenges (MHCs) in a private medical university. Methods: A crosssectional observational study was conducted to correlates the different determinants of university students with their knowledge towards MHCs in a private university in Malaysia. Validated questionnaires were distributed using a convenient stratified sampling technique among students studying in the different healthcare faculties, namely medicine, pharmacy and dentistry. The Statistical Package for Social Science (SPSS) Version 24.0 was used to analyze the data. Results: Among 284 study participants, male students had less adequate knowledge than females. The majority of the students from the studied faculties had adequate knowledge of MHCs. Students of the age group of 25-30 years had adequate knowledge of $\mathrm{MHCs}$. Multiple logistic regression revealed that statistically significant differences $(p<0.05)$ were present among the three studied variables
\end{abstract}

i.e., faculty, year of education and healthcare professionals in the family Conclusion: Overall good knowledge of MHCs was observed among the studied cohort of the healthcare students of the private medical university. The present study concluded that faculty, year of education and healthcare professionals in the family were the observed determinants of knowledge about MHCs among the study participants.

Key words: Determinants, Knowledge, Mental health challenges, MHCs, Healthcare students.

\section{Correspondence}

\section{Dr. Muhammad Shahid Iqbal}

Department of Clinical Pharmacy, College of Pharmacy, Prince Sattam bin

Abdulaziz University, Al-kharj, 11942, SAUDI ARABIA

Phone no: +966-53-7014420

Email: drmmsiabal@gmail.com

DOI: 10.5330/ijpi.2020.3.73

\section{INTRODUCTION}

The university years of an individual are emotionally and intellectually more demanding than almost any other stage of education. At this stage, an individual faces many pressures and challenges that pose a variety of physical, social and emotional difficulties. ${ }^{1-3}$ The mental health of university students is of increasing concern globally and the most important group that must have a wider knowledge about mental health challenges (MHCs) are the healthcare students i.e. medical, dental and pharmacy students. ${ }^{2,3}$

In the past, a few studies had been done about MHCs and according to the literature they were mainly focused on the prevalence rate and of mental health problems and their challenges. ${ }^{3,4}$ The knowledge about the MHCs including the treatment or strategies to resolve them are still less among the students even the public. ${ }^{2-4}$ Most MHCs have their peak onset during young adulthood. Kessler et al. observed that by the age of 25 years, $75 \%$ of those who will have MHCs have had their first onset. ${ }^{5}$ Among traditional students, the significant disruptions associated with attending university may exacerbate current psychopathology that first manifested in childhood and/or trigger its first onset. ${ }^{6-8}$ Similarly, nontraditional students who may have to attend to the demands of their numerous roles (work and family) may experience an exacerbation of their symptoms or a relapse. ${ }^{7,9}$

MHCs also bring a lot of dangerous effects in daily routines like depression, tension, anxiety and numerous psychic problems. ${ }^{7-9}$ Nowadays, several university students are facing mental health problems no matter what study in which university., ${ }^{4,9}$ Studies have also shown that mental health problems among university students are increasing in number as well as in severity. ${ }^{7,8}$ Since the mental health of university students is of increasing concern so they must have a wider knowledge about this problem..$^{9,10}$ They should also be aware of all the symptoms and their treatments to treat MHCs. ${ }^{10}$ Furthermore, university students from healthcare faculties should have more knowledge as compared to the other non-healthcare students because after graduation they will be directly involved in the healthcare system to treat the patients. This study aimed to evaluate different determinants of healthcare students' knowledge towards the MHCs in a private university in Malaysia.

\section{MATERIALS AND METHODS}

This study used a validated instrument to assess the effect of different detainments of knowledge regarding MHCs among healthcare students. The research was carried out over nine months using a convenient stratified sampling to obtain the desired sample from three healthcare faculties with different gender and age groups. Participants' consent was obtained from those who were willing to participate before the start of the study. The initial questionnaire was initially prepared after an extensive literature review and the modified questionnaire was later validated by experienced professionals in the field and an improved and validated version was obtained for data collection.

The knowledge and practice part of the questionnaire consisted of fifteen multiple-choice questions in a conventional format of one correct answer and three wrong answers. Participants were required to read and choose their one preference from three choices, based on their understanding and knowledge. The participants' response was scored based on their correct and incorrect answers. The scoring criterion was adapted from former studies and a score of 1 was credited to each correct answer and 
0 for incorrect answers. ${ }^{11,12}$ Correct answers $0-8$ were categorized as inadequate knowledge and 9-15 correct answers as adequate knowledge. All aspects of the study protocol as per the concerned committee were followed before and during the study. Those students who refused to take part were not forced to participate. The distribution of consent form was only done to the participants who were voluntarily willing to participate. All of the information was strictly confidential, protected and was used for the research only.

\section{Statistical Analyses}

Means and standard deviations were calculated for continuous variables, whereas the categorical variables were presented as frequencies and percentages. The Chi-square test was used to observe the significance between categorical variables and a $p$-value of $<0.05$ was considered statistically significant. A multivariate logistic regression model with the Wald statistical criteria was used to obtain determinants (predictors). The variables that had a $p$-value $<0.05$ in the univariate analysis were included in the multivariate analysis. The fit of the model was assessed by Hosmer Lemeshow and the overall classification percentage.

Table 1: Demographic characteristics of study participants $(n=284)$.

\begin{tabular}{lc}
\hline \multicolumn{1}{l}{ Variable } & $\mathrm{N}(\%)$ \\
\hline Gender & \\
Male & $104(36.6)$ \\
Female & $180(63.4)$ \\
Age groups & \\
$\leq 25$ years & $274(96.4)$ \\
$>25$ years & $10(3.6)$ \\
Race & \\
Malay & $7(2.5)$ \\
Chinese & $212(74.6)$ \\
Indian & $60(21.2)$ \\
Others & $5(1.7)$ \\
Faculty & \\
Medicine & $95(33.5)$ \\
Pharmacy & $94(33.0)$ \\
Dentistry & $95(33.5)$ \\
Year of education & $102(71.2)$ \\
Pre-final & $108(38.1)$ \\
Final & $110(38.8)$ \\
Residence & \\
Hosteller & $143(50.3)$ \\
Non- Hosteller & \\
Parents' education & \\
$\leq$ Primary & \\
Pre-university & \\
University & \\
Healthcare professionals in family & \\
\hline
\end{tabular}

\section{RESULTS}

Table 1 shows the demographic details of the study participants. According to the results of this study, the demographics characteristics were varied among the participants. A total of 284 samples were obtained consisted of $104(36.6 \%)$ males and 180 (63.4\%) females. Filled-up responses were evenly collected from the three selected student faculties, namely the faculty of medicine 95 (33.5\%), pharmacy 94 (33.1\%) and dentistry 95 (33.5\%).

Table 2 denotes the knowledge score with the percentage from the study participants as adequate and inadequate knowledge. There were a total of 15 different knowledge questions were asked regarding MHCs from the study participants.

Table 3 shows the determinants of knowledge with univariate analysis and multivariate regression model analysis. According to the univariate analysis, five variables were statistically significant. In multivariate logistic regression analysis, three variables, faculty, year of education and healthcare professionals in the family were statistically significant.

Table 2: Knowledge response among study participants.

\begin{tabular}{lcc}
\hline \multicolumn{1}{c}{ Variables } & \multicolumn{2}{c}{ Knowledge of MHCs (N \%) } \\
\hline Gender & Adequate & Inadequate \\
Male & $93(89.4)$ & $11(10.6)$ \\
Female & $172(95.6)$ & $8(4.4)$ \\
Age groups & & \\
$\leq 25$ years & $255(93.1)$ & $19(6.9)$ \\
$>$ 25 years & $7(70.0)$ & $3(30.0)$ \\
Race & & \\
Malay & $4(57.1)$ & $3(42.9)$ \\
Chinese & $194(91.5)$ & $18(8.5)$ \\
Indian & $45(75.0)$ & $15(25.0)$ \\
Others & $4(80.0)$ & $1(20.0)$ \\
Faculty & & \\
Medicine & $92(96.8)$ & $3(3.2)$ \\
Pharmacy & $88(93.6)$ & $6(6.3)$ \\
Dentistry & $83(87.4)$ & $12(12.6)$ \\
Year of education & & \\
Pre-final & $190(94.1)$ & $12(5.9)$ \\
Final & & \\
Residence & $122(85.3)$ & $21(14.6)$ \\
Hosteller & $131(92.9)$ & $10(7.1)$ \\
Non- Hosteller & & \\
Parents' education & & \\
$\leq$ Primary & & \\
Pre-university & & \\
University & & \\
Healthcare professionals in family & & \\
No & & \\
\hline
\end{tabular}




\section{DISCUSSION}

The knowledge evaluation showed that the majority of the students from each faculty had adequate knowledge about MHCs. A total of 92 (96.8\%) medicine, 90 (95.7\%) pharmacy and 83 (87.4\%) dentistry students had adequate knowledge. In comparison, dentistry students had the least knowledge as compared to medical and pharmacy students. Similar to the current study findings, another study showed that the dentistry students had higher levels of stress and lower grades for clinical competencies and contextual understandings. ${ }^{13}$ Furthermore, it also reported that dentistry students had less knowledge about mental health problems as evident in our study. ${ }^{13,14}$

Though there was not more than $1 \%$ difference between pre-final and final students for adequate knowledge, yet pre-final students considered adequate knowledge than final students. Only 9 (6.3\%) out of 143 prefinal students and 10 (7.1\%) out of 141 final students had inadequate knowledge. In contrast to the current study, a study was conducted in the United States had shown that education had positive effects on reducing stigma among the students. The higher levels of education were more effective in reducing stigma regarding MHCs. ${ }^{15}$
In univariate analysis, our study found significant differences $(p<0.05)$ in gender, faculty, year of education, parents' education and healthcare professionals in family. In gender (COR 2.562; $p=0.041$ ) where only $11(10.6 \%)$ male and $8(4.4 \%)$ female students scored as inadequate knowledge. The result showed that more female students had adequate knowledge as compared with male students. Moreover, another study also reported similar outcomes that female students had more adequate knowledge then the males. ${ }^{16}$ In faculty, the dentistry students had more inadequate knowledge of MHCs than the other two faculties. The pharmacy students had better knowledge with (COR 1.823; $p=0.049)$ than the dentistry students (COR 5.463; $p=0.003$ ). Our study results were similar to another study conducted by Al-Mamun et al. ${ }^{17}$

In univariate analysis findings, parents' education was also found as statistically significant between primary or low-level education and secondary and university levels. For pre-university education (COR $1.352 ; p=0.039)$ whereas for university-level education (COR 2.318; $p=$ 0.047 ) were observed which clearly showed that statistically significant differences were present among them.

In our study, pure determinants of adequate knowledge were obtained by adjusting or controlling confounders through the multivariate logistic

Table 3: Determinants of knowledge about mental health challenges.

\begin{tabular}{|c|c|c|c|c|}
\hline \multirow[t]{2}{*}{ Variables } & \multicolumn{2}{|c|}{ Univariate analysis } & \multicolumn{2}{|c|}{ Multivariate analysis } \\
\hline & COR $(95 \% \mathrm{CI})$ & $P$-value & AOR $(95 \% \mathrm{CI})$ & $P$-value \\
\hline \multicolumn{5}{|l|}{ Gender } \\
\hline Male & Referent & & Referent & \\
\hline Female & $2.562(0.49-8.67)$ & 0.041 & $2.026(0.67-5.21)$ & 0.261 \\
\hline \multicolumn{5}{|l|}{ Age groups } \\
\hline$\leq 25$ years & Referent & & & \\
\hline$>25$ years & $0.321(0.22-1.98)$ & 0.651 & - & - \\
\hline \multicolumn{5}{|l|}{ Race } \\
\hline Malay & Referent & & & \\
\hline Chinese & $0.836(0.29-1.61)$ & 0.783 & - & - \\
\hline Indian & $1.501(1.32-2.21)$ & 0.523 & - & - \\
\hline Others & - & - & - & - \\
\hline \multicolumn{5}{|l|}{ Faculty } \\
\hline Medicine & Referent & & Referent & \\
\hline Pharmacy & $1.823(0.94-6.39)$ & 0.049 & $1.019(0.42-5.81)$ & 0.231 \\
\hline Dentistry & $5.463(3.93-9.23)$ & 0.003 & $4.658(2.69-7.51)$ & 0.042 \\
\hline \multicolumn{5}{|l|}{ Year of education } \\
\hline Pre-final & Referent & & Referent & \\
\hline Final & $2.439(1.32-5.32)$ & 0.006 & $2.241(1.12-4.52)$ & 0.034 \\
\hline \multicolumn{5}{|l|}{ Residence } \\
\hline Hosteller & Referent & & & \\
\hline Non- Hosteller & $0.826(0.73-2.23)$ & 0.215 & - & - \\
\hline \multicolumn{5}{|l|}{ Parents' education } \\
\hline$\leq$ Primary & Referent & & Referent & \\
\hline Pre-university & $1.352(0.12-2.29)$ & 0.039 & $2.489(1.12-3.52)$ & 0.482 \\
\hline University & $2.318(1.94-4.62)$ & 0.047 & $1.329(1.28-4.22)$ & 0.347 \\
\hline \multicolumn{5}{|c|}{ Healthcare professionals in family } \\
\hline Yes & Referent & & Referent & \\
\hline No & $2.253(1.61-6.47)$ & 0.001 & $2.091(1.19-5.18)$ & 0.021 \\
\hline
\end{tabular}

$\mathrm{SD}=$ Standard Deviation, $\mathrm{COD}=$ Crude Odds Ratio, $\mathrm{AOD}=$ Adjusted Odds Ratio, $\mathrm{CI}=$ Confidence Interval 
Iqbal, et al:: Determinants Affecting Knowledge of HCSs towards MHCs

regression model. In logistic regression, it was inferred that faculty, year of education and healthcare professionals in the family were the pure determinants of knowledge regarding MHCs among healthcare students. The odds for the faculty (AOR 4.658; $p=0.042$ ), the year of education (AOR 2.241; $p=0.034$ ) and the healthcare professionals in the family (AOR 2.091; $p=0.021$ ) were reported when adjusted for the other studied demographic variables. From multiple logistics regression analysis, year of education had a greater effect on the knowledge about MHCs among the study participants. Similarly, with an increase in years of education, age will also be increased which has also effect on MHCs, in terms of developing negative ideas and even suicidal attempts. ${ }^{18}$ One study reported that existing MHCs or new one cases can be further aggravated by changing place of living as moving away from home to university was considered as a major life transition ${ }^{19,20}$ According to other studies, around $70 \%$ of diagnosable mental disorders usually began by the age of $25 .^{21,22}$ Presence of healthcare professionals in the family also helps in minimizing MHCs among the university students. The findings of current research also indicated that participants coming from families who had healthcare professionals had high knowledge and awareness about MHC than the rest.

Like various other similar studies, this was a cross-sectional study whereby its generalizability was limited by the size of the studied population. Hence, the results cannot be projected to the entire country as this study was only done in a selected medical university. A detailed follow-up study can be done to further evaluate the different determinants of knowledge about MHCs among students in other universities in Malaysia. Nevertheless, despite some limitations, there are notable strengths and merits of the current study. This study about predictors of knowledge regarding MHCs was not a substitute for any treatment or management but it will definitely further help in promoting awareness about MHCs among university students. Hopefully, this study will help and motivate officials and students to happier and healthier university lives. This study also underlined the dire need for students' counseling and raising awareness regarding MHCs among them especially the healthcare students.

\section{CONCLUSION}

The present study reported that faculty, year of education and healthcare professionals in the family were the determinants (predictors) of knowledge about MHCs among healthcare university students in Malaysia. This study was novel among its type as there was no earlier study reported to determine predictors of knowledge about MHCs among healthcare university students in Malaysia.

\section{ACKNOWLEDGEMENT}

The authors would like to thank the Deanship of Scientific Research at Prince Sattam bin Abdulaziz University, Alkharj, Saudi Arabia, for the support in the publication of this manuscript. The authors would also like to express their sincere gratitude to all of the participants involved in this study in any capacity.

\section{CONFLICT OF INTEREST}

The authors declare no conflict of interest.

\section{ABBREVIATIONS}

MHCs: Mental Health Challenges; ADA: American Dental Association; SPSS: Statistical Package for Social Sciences; CI: Confidence Interval; OR: Odds Ratio; COR: Crude Odds Ratio; AOR: Adjusted Odds Ratio.

\section{REFERENCES}

1. Räikkönen K, Matthews KA, Flory JD, Owens JF, Gump BB. Effects of optimism, pessimism and trait anxiety on ambulatory blood pressure and mood during everyday life. J Pers Soc Psychol. 1999;76(1):104.

2. Maser B, Danilewitz M, Guérin E, Findlay L, Frank E. Medical Student Psychological Distress and Mental Illness Relative to the General Population: A Canadian Cross-Sectional Survey. Acad Med. 2019;94(11):1781-91.

3. Eisenberg D, Gollust SE, Golberstein E, Hefner JL. Prevalence and correlates of depression, anxiety and suicidality among university students. Am J Orthopsychiatry 2007;77(4):534-42

4. Macaskill A. The mental health of university students in the United Kingdom. $\mathrm{Br}$ J Guid Counc. 2013;41(4):426-41.

5. Kessler RC, Berglund P, Demler O, Jin R, Merikangas KR, Walters EE. Lifetime prevalence and age-of-onset distributions of DSM-IV disorders in the National Comorbidity Survey Replication. Arch Gen Psychiatry. 2005;62(6):593-602.

6. Wahl O, Rothman J, Brister T, Thompson C. Changing student attitudes about mental health conditions: NAMI ending the silence. Stigma and Health. 2019;4(2):188

7. Eisenberg D, Gollust SE, Golberstein E, Hefner JL. Prevalence and correlates of depression, anxiety and suicidality among university students. Am J Orthopsychiatry. 2007;77(4):534-42.

8. Vaingankar JA, Rekhi G, Subramaniam M, Abdin E, Chong SA. Age of onset of life-time mental disorders and treatment contact. Soc Psychiatry Psychiatr Epidemiol. 2013;48(5):835-43.

9. Blanco C, Okuda M, Wright C, Hasin DS, Grant BF, Liu SM, et al. Mental health of college students and their non-college-attending peers: Results from the national epidemiologic study on alcohol and related conditions. Arch Gen Psychiatry. 2008;65(12):1429-37.

10. Saleem S, Mahmood Z, Naz M. Mental health problems in university students: A prevalence study. FWU J Soc Sci. 2013;7(2):124.

11. Jerger J, Johnson K, Jerger S. Effect of Response Criterion on Measures of Speech: Understanding in the Elderly. Ear Hear. 1988;9(2):49-56.

12. Sanders AE, Lushington K. Effect of perceived stress on student performance in dental school. J Dent Educ. 2002;66(1):75-81.

13. Stormon N, Ford PJ, Eley DS. DREEM-ing of dentistry: Students' perception of the academic learning environment in Australia. Eur J Dent Educ. 2019;23(1):3541.

14. Eisenberg D, Gollust SE, Golberstein E, Hefner JL. Prevalence and correlates of depression, anxiety and suicidality among university students. Am J Orthopsychiatry. 2007;77(4):534-42.

15. Wahl O, Rothman J, Brister T, Thompson C. Changing student attitudes about mental health conditions: NAMI ending the silence. Stigma and Health. 2019;4(2):188

16. Mokhtari M, Dehghan SF, Asghari M, Ghasembaklo U, Mohamadyari G, Azadmanesh SA, et al. Epidemiology of mental health problems in female students: A questionnaire survey. J Epidemiol Glob Health. 2013;3(2):83-8.

17. Al-Mamun A, Debnath P, Siddika F, Islam MJ. Knowledge of food habit and other daily habit are the determinants of health status: A study among the students of Chattogram regions. Asian J Health Sci. 2019;5(2):10-.

18. Cash SJ, Bridge JA. Epidemiology of youth suicide and suicidal behavior. Current Opinion in Pediatrics. 2009;21(5):613.

19. Marcus $\mathrm{M}$, Westra $\mathrm{H}$. Mental health literacy in Canadian young adults: Results of a national survey. Can J Commun Ment Health. 2012;31(1):1-5.

20. Eisenberg D, Speer N, Hunt JB. Attitudes and beliefs about treatment among college students with untreated mental health problems. Psychiatr Serv. 2012;63(7):711-3.

21. Farrer L, Leach L, Griffiths KM, Christensen $H$, Jorm AF. Age differences in mental health literacy. BMC Public Health. 2008;8(1):125.

22. Kitzrow MA. The mental health needs of today's college students: Challenges and recommendations. NASPA J. 2003;41(1):167-81. 